\title{
Survival prediction in patients undergoing radionuclide therapy based on intratumoral somatostatin-receptor heterogeneity
}

\author{
Rudolf A. Werner ${ }^{1, *}$, Constantin Lapa ${ }^{1, *}$, Harun Ilhan ${ }^{2}$, Takahiro Higuchi ${ }^{1}$, Andreas \\ K. Buck ${ }^{1}$, Sebastian Lehner ${ }^{2}$, Peter Bartenstein ${ }^{2}$, Frank Bengel ${ }^{3}$, Imke Schatka ${ }^{4}$, \\ Dirk O. Muegge ${ }^{5}$, László Papp ${ }^{6}$, Norbert Zsótér7, Tobias Große-Ophoff ${ }^{8}$, Markus \\ Essler ${ }^{8}$ and Ralph A. Bundschuh ${ }^{8}$ \\ ${ }^{1}$ Department of Nuclear Medicine, University Hospital Würzburg, Würzburg, Germany \\ 2 Department of Nuclear Medicine, Ludwig-Maximilians-University Munich, Munich, Germany \\ ${ }^{3}$ Department of Nuclear Medicine, Hannover Medical School, Hannover, Germany \\ ${ }^{4}$ Department of Nuclear Medicine, Charité - Universitätsmedizin Berlin, Berlin, Germany \\ ${ }^{5}$ University of Applied Sciences, Hamburg, Germany \\ ${ }^{6}$ Department of Nuclear Medicine, Medical University of Vienna, Vienna, Austria \\ 7 Mediso Medical Imaging Systems Ltd., Budapest, Hungary \\ ${ }^{8}$ Department of Nuclear Medicine, University Medical Center Bonn, Bonn, Germany \\ * These authors have contributed equally to this work \\ Correspondence to: Ralph A. Bundschuh, email: ralph.bundschuh@ukb.uni-bonn.de \\ Keywords: neuroendocrine tumor, tumor heterogeneity, textural parameters, SSTR-PET/CT, radiopeptide therapy \\ Received: September 20,2016 Accepted: September 26, $2016 \quad$ Published: October 02, 2016
}

\section{ABSTRACT}

The NETTER-1 trial demonstrated significantly improved progression-free survival (PFS) for peptide receptor radionuclide therapy (PRRT) in neuroendocrine tumors (NET) emphasizing the high demand for response prediction in appropriate candidates. In this multicenter study, we aimed to elucidate the prognostic value of tumor heterogeneity as assessed by somatostatin receptor (SSTR)-PET/CT. 141 patients with SSTR-expressing tumors were analyzed obtaining SSTR-PET/CT before PRRT (1-6 cycles, ${ }^{177} \mathrm{Lu}$ somatostatin analog). Using the Interview Fusion Workstation (Mediso), a total of $\mathbf{8 7 2}$ metastases were manually segmented. Conventional PET parameters as well as textural features representing intratumoral heterogeneity were computed. The prognostic ability for PFS and overall survival (OS) were examined. After performing Cox regression, independent parameters were determined by ROC analysis to obtain cut-off values to be used for Kaplan-Meier analysis. Within follow-up (median, 43.1 months), 75 patients showed disease progression (median, $22.2 \mathrm{~m}$ ) and 54 patients died (median, $27.6 \mathrm{~m}$ ). Cox analysis identified 8 statistically independent heterogeneity parameters for time-to-progression and time-to-death. Among them, the textural feature Entropy predicted both PFS and OS. Conventional PET parameters failed in response prediction. Imaging-based heterogeneity assessment provides prognostic information in PRRT candidates and outperformed conventional PET parameters. Its implementation in clinical practice can pave the way for individualized patient management.

\section{INTRODUCTION}

Over the past decades, a rising incidence of neuroendocrine tumors (NET) has been reported [1]. With a delay in diagnosis of 5-7 years, NET typically present at advanced stages. In clinical routine, physicians often have to rely on single tumor biopsies for treatment decisions and might therefore be prone to sampling bias which ultimately leads to either misdiagnosis or underestimation of therapeutic response $[2,3]$. Therefore, non-invasive, whole-body assessment of tumor heterogeneity 
Table 1: Detailed patients' characteristics. Characteristic

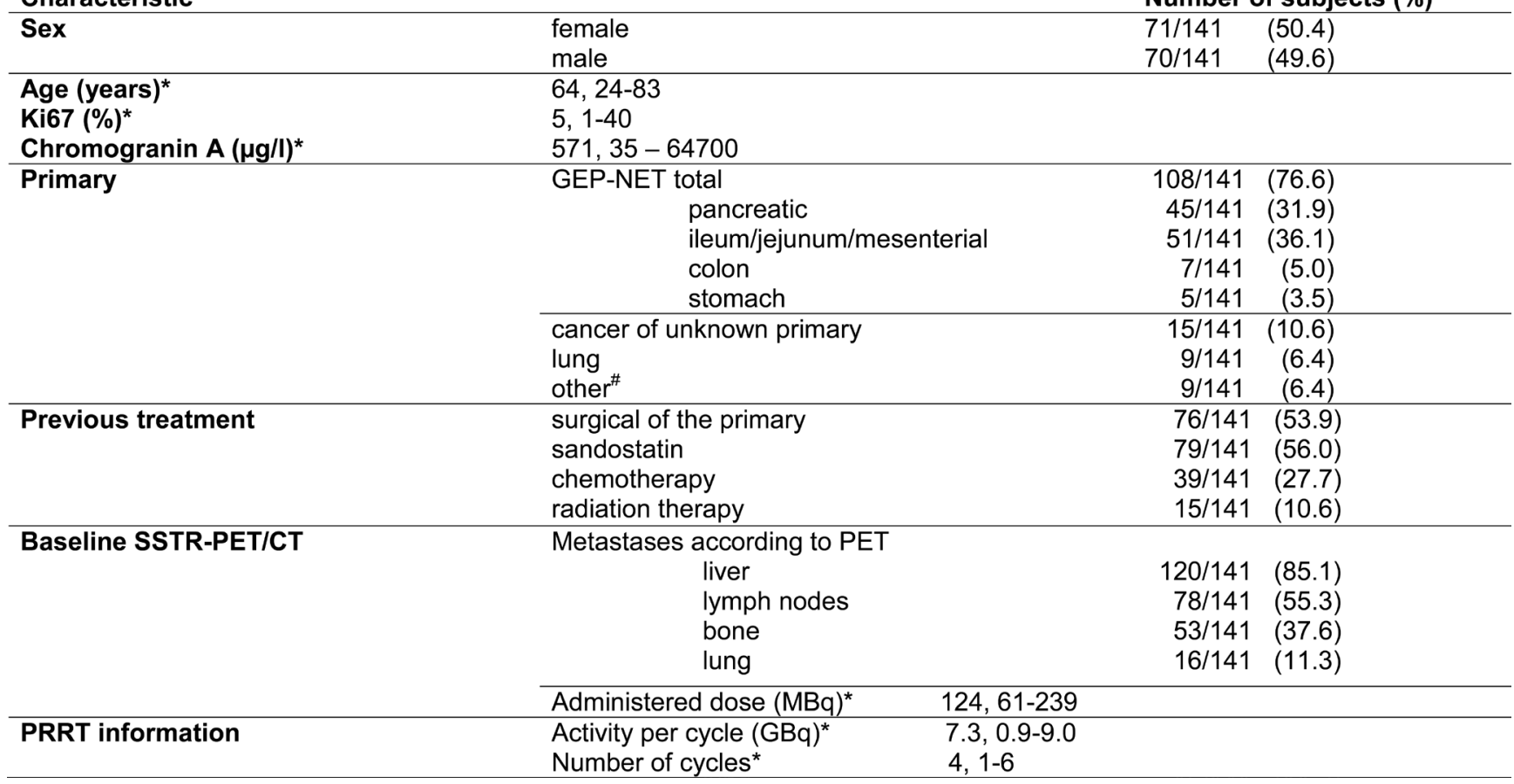

* = median and range is given, \# = including meningeoma, hemangioendothelioma, pheochromocytoma, medullary thyroid carcinoma and pituitary tumor. GBq $=$ Gigabecquerel, GEP-NET = gastroenteropancreatic neuroendocrine tumors, $\mathrm{MBq}=$ Megabecquerel, PRRT = Peptide Receptor Radionuclide Therapy, SSTR-PET/CT = somatostatin receptor positron emission tomography/computed tomography.

is highly desirable. Due to its ability to visualize functional alterations on a molecular level instead of pure morphological characteristics, positron emission tomography (PET) has proven its prognostic value in risk stratification for several types of cancer [4-6].

Recently, the NETTER-1 trial (ClinicalTrials.gov Identifier: NCT01578239) demonstrated significantly improved progression-free survival (PFS) for NET patients treated with the $\beta$-emitter labeled somatostatin analog ${ }^{177} \mathrm{Lu}$-DOTA-D-Phe-Tyr3-octreotate (DOTATATE) in advanced midgut NET [7-10]. Thus, rising numbers of peptide receptor radionuclide therapy (PRRT) can be expected in the next years.

As a prerequisite, pre-therapeutic somatostatin receptor (SSTR)-PET/computed tomography (CT) is mandatory to confirm adequate receptor density on the tumor cell surface $[11,12]$. Consequently, the imaging agent ${ }^{68} \mathrm{Ga}$-DOTATATE was recently approved by the FDA which will also promote use of PRRT and simultaneously emphasizes the need for reliable response prediction prior to treatment initiation.

In this present multi-center trial, we aimed to elucidate the prognostic capability of intratumoral heterogeneity parameters assessed by baseline SSTR-PET/ $\mathrm{CT}$ in patients scheduled for radionuclide therapy.

\section{RESULTS}

A total of 141 SSTR-PET scans were performed prior to PRRT. Baseline PET was positive in all patients as a prerequisite for treatment initiation. 120/141 (85.1\%) subjects suffered from liver metastases, more than half of the cohort demonstrated lymph node metastases $(78 / 141$, $55.3 \%$ ), one third suffered from bone lesions (53/141, $37.6 \%)$ and $16 / 141(11.3 \%)$ demonstrated pulmonary metastases (Table 1).

Within follow-up (median, 43.1 months, range, 22.3 - $89.8 \mathrm{~m}), 75 / 139$ subjects $(54.0 \%)$ experienced progressive disease. On average, progression was detected at a median of $22.2 \mathrm{~m}$ after the pre-therapeutic baseline PET scan (mean, $27.1 \mathrm{~m}$, range, 4 days - $85.2 \mathrm{~m}$ ). 54/141 $(38.3 \%)$ patients died from their cancer after a median of $27.6 \mathrm{~m}$ (mean, $31.4 \mathrm{~m}$, range, 4 days $-85.2 \mathrm{~m}$ ). The median proliferation index $\mathrm{Ki} 67$ in those patients was 5\% (range, 1-40\%).

\section{Correlation of clinical parameters with both PFS and $\mathrm{OS}$}

Cox regression analysis of clinical parameters (as given in Table 1) was performed. Regarding PFS and OS, cumulative dose was the only parameter reaching significance (PFS, $p<0.02$, OS, $p<0.01$ ). Moreover, 
Table 2: Receiver Operating Characteristics (ROC) analysis for Progression-Free (PFS) and Overall Survival (OS) for conventional and heterogeneity positron emission tomography (PET) parameters.

\begin{tabular}{|c|c|c|c|c|c|c|c|c|}
\hline & Parameter & for & AUC & $95 \%$ CI & $\begin{array}{c}\text { Sensitivity } \\
(\%)\end{array}$ & \begin{tabular}{|c}
$\begin{array}{c}\text { Specificity } \\
(\%)\end{array}$ \\
\end{tabular} & Cut-off & $p$-value \\
\hline $\bar{\Xi} \quad \tilde{0}$ & SUVmax & $\begin{array}{l}\mathrm{PFS} \\
\mathrm{OS} \\
\end{array}$ & $\begin{array}{l}0.53 \\
0.50 \\
\end{array}$ & $\begin{array}{l}0.45-0.62 \\
0.42-0.59 \\
\end{array}$ & $\begin{array}{l}47 \\
43 \\
\end{array}$ & $\begin{array}{l}66 \\
69 \\
\end{array}$ & $\begin{array}{l}>23.6 \\
>25.6 \\
\end{array}$ & $\begin{array}{ll}0.51 \\
0.98 \\
\end{array}$ \\
\hline 氮㫐芯 & SUVmean & $\begin{array}{l}\mathrm{PFS} \\
\mathrm{OS} \\
\end{array}$ & $\begin{array}{l}0.50 \\
0.52 \\
\end{array}$ & $\begin{array}{l}0.42-0.59 \\
0.44-0.61 \\
\end{array}$ & $\begin{array}{l}28 \\
76 \\
\end{array}$ & $\begin{array}{l}61 \\
40 \\
\end{array}$ & $\begin{array}{l}\leq 10.3 \\
\leq 12.3 \\
\end{array}$ & $\begin{array}{l}0.99 \\
0.66 \\
\end{array}$ \\
\hline లే & TRE & $\begin{array}{l}\mathrm{PFS} \\
\mathrm{OS} \\
\end{array}$ & $\begin{array}{l}0.57 \\
0.64 \\
\end{array}$ & $\begin{array}{l}0.48-0.65 \\
0.56-0.72 \\
\end{array}$ & $\begin{array}{l}32 \\
44 \\
\end{array}$ & \begin{tabular}{|l}
84 \\
82 \\
\end{tabular} & $\begin{array}{l}\leq 1637 \\
\leq 1977 \\
\end{array}$ & $\begin{array}{l}0.16 \\
0.003 * \\
\end{array}$ \\
\hline \multirow{16}{*}{ 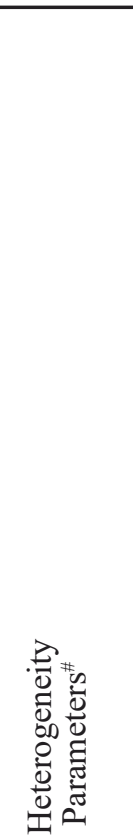 } & \multirow{2}{*}{ Coefficient of Variation } & PFS & 0.53 & $0.44-0.61$ & 48 & 64 & $>0.3559$ & 0.58 \\
\hline & & $\mathrm{OS}$ & 0.53 & $0.45-0.62$ & 28 & 90 & $>0.4794$ & 0.55 \\
\hline & \multirow{2}{*}{ Skewness } & PFS & 0.52 & $0.435-0.607$ & 28 & 88 & $>0.8465$ & 0.66 \\
\hline & & OS & 0.52 & $0.44-0.6$ & 35 & 87 & $>0.8465$ & 0.71 \\
\hline & \multirow{2}{*}{ Entropy } & PFS & 0.60 & $0.52-0.68$ & 37 & 83 & $\leq 5.6443$ & $0.04 *$ \\
\hline & & $\mathrm{OS}$ & 0.70 & $0.61-0.77$ & 65 & 74 & $\leq 6.1767$ & $0.0001^{*}$ \\
\hline & \multirow{2}{*}{ Homogeneity } & PFS & 0.61 & $0.51-0.68$ & 39 & 88 & $>0.0175$ & $0.020^{*}$ \\
\hline & & OS & 0.67 & $0.62-0.78$ & 61 & 78 & $>0.0118$ & 0.0004* \\
\hline & \multirow{2}{*}{ Correlation } & PFS & 0.64 & $0.55-0.72$ & 42 & 86 & $\leq 0.1581$ & $0.004^{*}$ \\
\hline & & OS & 0.69 & $0.6-0.77$ & 70 & 68 & $\leq 0.4184$ & $0.0001^{*}$ \\
\hline & \multirow{2}{*}{ Contrast } & PFS & 0.51 & $0.42-0.60$ & 32 & 81 & $\leq 10433$ & 0.84 \\
\hline & & OS & 0.54 & $0.46-0.26$ & 35 & 82 & $\leq 5186.45$ & 0.51 \\
\hline & \multirow{2}{*}{$\begin{array}{l}\text { Short Zone } \\
\text { Emphasis }\end{array}$} & PFS & 0.60 & $0.52-0.69$ & 56 & 64 & $>0.9998$ & $0.031 *$ \\
\hline & & OS & 0.62 & $0.53-0.70$ & 53 & 78 & $>0.9999$ & $0.024 *$ \\
\hline & \multirow{2}{*}{ Size Variation } & PFS & 0.59 & $0.5-0.68$ & 43 & 83 & $>0.0004$ & 0.06 \\
\hline & & OS & 0.70 & 0.56 .0 .72 & 44 & 82 & $\leq 1976.855$ & $<0.0001^{*}$ \\
\hline
\end{tabular}

As obtained by Cox multiparametric analysis, only the above-mentioned heterogeneity parameters were independent from each other. Of the whole cohort $(\mathrm{n}=141), 75$ patients demonstrated progressive disease, 54 died. Compared to conventional parameters, heterogeneity parameters (such as Entropy, Homogeneity, Correlation, Short Zone Emphasis, Size Variation) demonstrated higher AUC values. Additionally, these imaging-based features reached a statistically significant distinction between responders and non-responders. $*=$ statistically significant, $\#=$ independent according to Cox analysis. $\mathrm{CI}=$ confidence interval, $\mathrm{PET}=$ positron emission tomography, $\mathrm{SUV}_{\text {mean } / \max }=$ mean $/$ maximum standardized uptake value, TRE $=$ Tissue Receptor Expression.

several investigated clinical features trended to be significant (Ki67, PFS, $p=0.09$; CgA, OS, $p=0.06$ ).

\section{Correlation of PET parameters with both PFS and $\mathrm{OS}$}

In Cox hazard analysis, the only parameter that showed significant correlation for both PFS $(p=0.02)$ and OS ( $p=0.0002)$ was Entropy with Hazard Ratio (HR) of 0.59 and 0.35 , respectively. In addition, Skewness showed significant correlation $(p=0.04)$ with OS with an HR of 0.58 .

In Receiver Operating Characteristics (ROC) analysis of the independent parameters Entropy, Correlation, Short Zone Emphasis and Homogeneity demonstrated significant prognostic ability for PFS. Significant prognostic values for OS were found for
Entropy, Correlation, Homogeneity, Short Zone Emphasis and Size Variation. Of the investigated conventional PET parameters, Tissue Receptor Expression (TRE) was significant for OS $(p=0.003)$, whereas all other parameters failed in response prediction. Details can be found in Table 2 and selected ROC curves are shown in Supplementary Figure a.

Kaplan-Meier analysis using the threshold evaluated by ROC revealed a significant distinction between high- and low-risk patients for both PFS and OS for the following textural parameters: Entropy, Correlation, Short Zone Emphasis and Homogeneity. In addition, TRE showed a significant distinction for OS. Details including the negative and positive hazard ratios can be found in Table 3, respective Kaplan-Meier-plots for PFS are given in Figure 1 and for OS in Figure 2. An overview of the respective AUC values for both standard and heterogeneity PET parameters regarding PFS and OS are given in Table 
2.

\section{DISCUSSION}

In the present study, we investigated the prognostic value of PET-assessed tumor heterogeneity in patients scheduled for PRRT. Several textural characteristics like Entropy, Skewness, Correlation, Short Zone Emphasis and Homogeneity demonstrated superior diagnostic capability than standard PET parameters such as mean and maximum standardized uptake value $\left(\mathrm{SUV}_{\max } / \mathrm{SUV}_{\text {mean }}\right)$.

Several studies have reported the feasibility of texture analysis for heterogeneity assessment and its prognostic implication for individual patient outcome based on pretherapeutic CT and magnetic resonance imaging, e.g. in non-small cell lung carcinoma or prostate

A

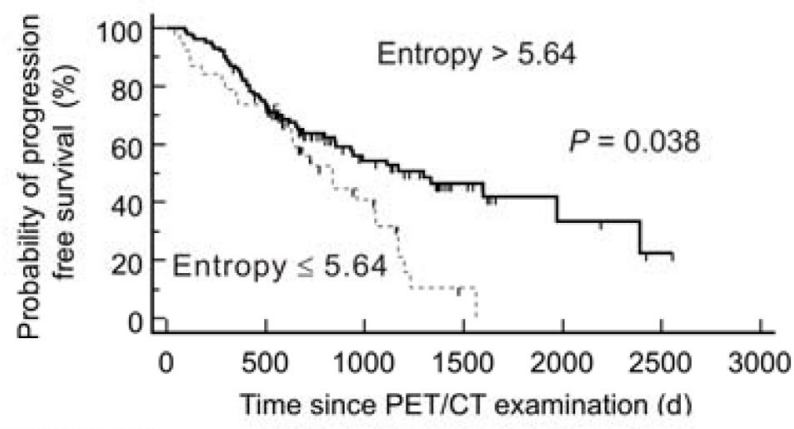

Number at risk:

\begin{tabular}{|l|r|r|r|r|r|r|r|}
\hline Time (d) & 0 & 500 & 1,000 & 1.500 & 2,000 & 2,500 & 3,000 \\
\hline Entropy > 5.64 & 101 & 73 & 33 & 13 & 4 & 1 & 0 \\
\hline Entropy $\leq 5.64$ & 38 & 27 & 10 & 1 & 0 & 0 & 0 \\
\hline
\end{tabular}

C

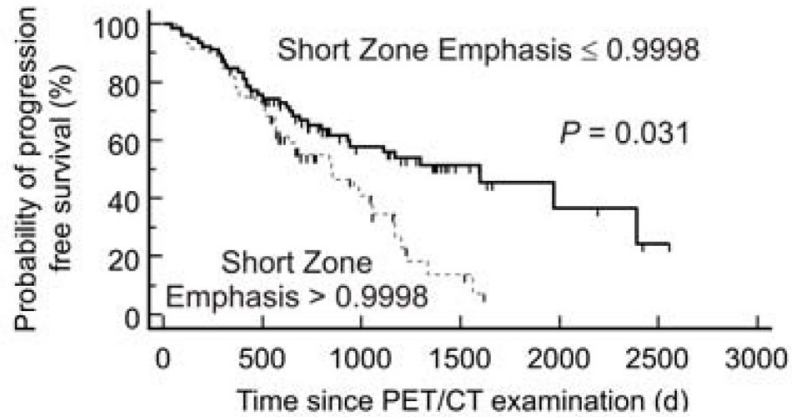

Number at risk:

\begin{tabular}{|l|r|r|r|r|r|r|r|}
\hline Time (d) & 0 & 500 & 1,000 & 1,500 & 2,000 & 2,500 & 3,000 \\
\hline $\begin{array}{l}\text { Short Zone } \\
\text { Emphasis } \leq 0.9998\end{array}$ & 79 & 57 & 29 & 11 & 4 & 1 & 0 \\
\hline $\begin{array}{l}\text { Short Zone } \\
\text { Emphasis >0.9998 }\end{array}$ & 60 & 43 & 14 & 3 & 0 & 0 & 0 \\
\hline
\end{tabular}

cancer [13-15]. Due to its ability to visualize whole-body tumor burden on a molecular level, PET-based tumor heterogeneity offers certain advantages for assessing intraindividual heterogeneity patterns in tumor biology. Consequently, prognostic capability of imaging-derived intratumoral heterogeneity using ${ }^{18} \mathrm{~F}-\mathrm{FDG}$ but also SSTR$\mathrm{PET} / \mathrm{CT}$ has been evaluated in several tumor entities, such as breast, rectal, thyroid or esophageal cancer $[4,6,16-$ 18]. In NET, given the complexity of various diagnostic procedures and treatment options, early identification of subjects likely to benefit from PRRT would be of great value for individualized treatment tailoring. As demonstrated in the present study, application of textural parameters could be helpful in differentiating high-risk from low-risk groups during PRRT. Strikingly, the 4 parameters Entropy, Correlation, Short Zone Emphasis and Homogeneity provided a significant distinction

B

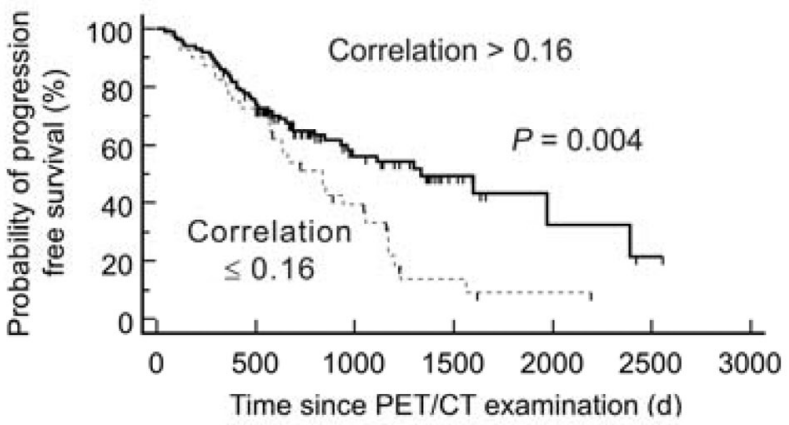

Number at risk:

\begin{tabular}{|l|r|r|r|r|r|r|r|}
\hline Time (d) & 0 & 500 & 1,000 & 1,500 & 2,000 & 2,500 & 3,000 \\
\hline Correlation >0.16 & 99 & 72 & 30 & 11 & 3 & 1 & 0 \\
\hline Correlation $\leq 0.16$ & 40 & 28 & 13 & 3 & 1 & 0 & 0 \\
\hline
\end{tabular}

D

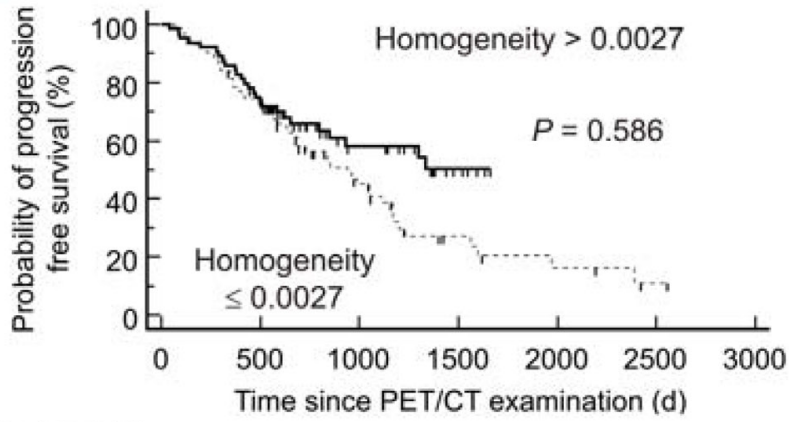

Number at risk:

\begin{tabular}{|l|r|r|r|r|r|r|r|}
\hline Time (d) & 0 & 500 & 1,000 & 1,500 & 2,000 & 2,500 & 3,000 \\
\hline $\begin{array}{l}\text { Homogeneity } \\
>0.0027\end{array}$ & 64 & 46 & 20 & 6 & 0 & 0 & 0 \\
\hline $\begin{array}{l}\text { Homogeneity } \\
\leq 0.0027\end{array}$ & 75 & 54 & 23 & 8 & 4 & 1 & 0 \\
\hline
\end{tabular}

Figure 1: Kaplan-Meier plots and number-at-risk tables for probability of Progression-Free Survival ( $n=139)$. Lowrisk group (solid lines) was identified by various textural parameters measured on somatostatin receptor positron emission tomography/ computed tomography (PET/CT) before Peptide Receptor Radionuclide Therapy. Cut-off values derived by Receiver operating characteristics analysis were used. $\mathrm{d}=$ days. 
between responders from non-responders (Table 3, Figure 1 and 2).

In NET, conventional CT-derived therapy response assessment failed to predict disease-related progression or survival [19, 20]. Regarding functional imaging, data is unequivocal: On the one hand, increasing uptake in SSTR scintigraphy $\left(\right.$ Octreoscan $\left.^{\circledR}\right)$ was reported as a significant predictor of PFS [21, 22]. On the other hand, conventional PET parameters like $\mathrm{SUV}_{\max }$ failed to predict time-to progression in SSTR-expressing tumor entities [23]. In line with this finding, Gabriel and colleagues also demonstrated no benefit from conventional ${ }^{68} \mathrm{Ga}$ DOTATOC PET parameters neither for response nor survival prediction in GEP NET patients scheduled for PRRT [24].

By contrast, heterogeneity parameters demonstrated

A

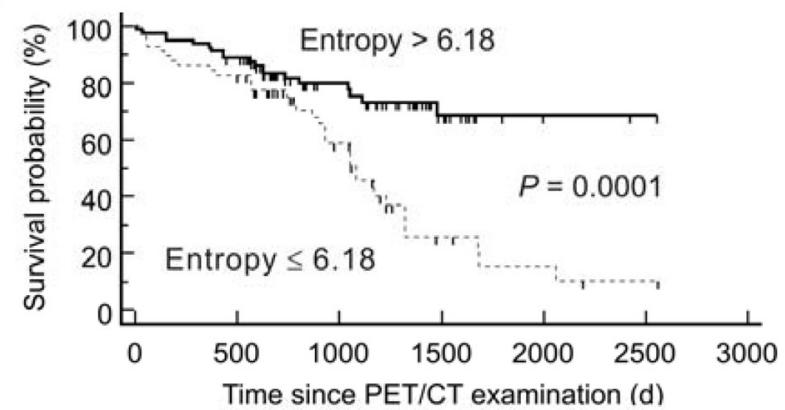

Number at risk:

\begin{tabular}{|l|r|r|r|r|r|r|r|}
\hline Time (d) & 0 & 500 & 1,000 & 1,500 & 2,000 & 2,500 & 3,000 \\
\hline Entropy >6.18 & 83 & 73 & 37 & 14 & 2 & 1 & 0 \\
\hline Entropy $\leq 6.18$ & 58 & 47 & 24 & 6 & 3 & 1 & 0 \\
\hline
\end{tabular}

C

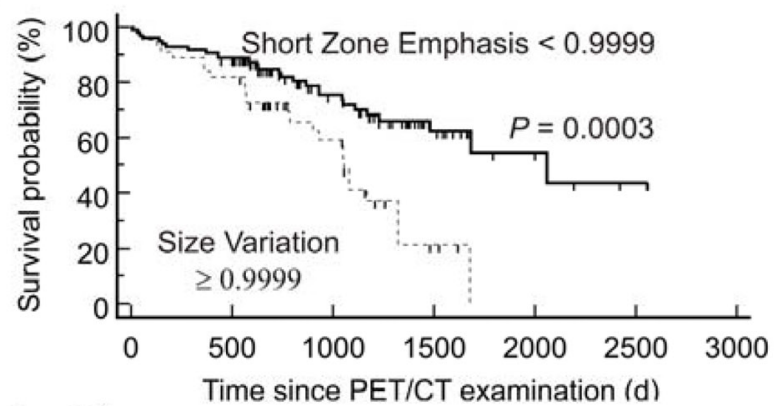

Number at risk:

\begin{tabular}{|l|r|r|r|r|r|r|r|}
\hline Time (d) & 0 & 500 & 1,000 & 1,500 & 2,000 & 2,500 & 3,000 \\
\hline $\begin{array}{l}\text { Short Zone } \\
\text { Emphasis < 0.9999 }\end{array}$ & 97 & 84 & 43 & 17 & 5 & 2 & 0 \\
\hline $\begin{array}{l}\text { Short Zone } \\
\text { Emphasis } \geq 0.9999\end{array}$ & 44 & 36 & 18 & 3 & 0 & 0 & 0 \\
\hline
\end{tabular}

prognostic value in this study, thereby, outperforming most conventional PET parameters. Of note, only the standard feature TRE proved useful in terms of OS prediction.

Not surprisingly, the cumulative treatment dose correlated significantly with both PFS and OS. This could be regarded as a kind of intra-observer quality control of our study: with increasing progression-free and overall survival, more treatment cycles are performed and, consequently, the administered dose rises.

Interestingly, well-established histology or serumbased parameters of tumor aggressiveness or burden, such as the proliferation index Ki67 (PFS, $p=0.09$ ) or CgA (OS, $p=0.06)$, failed to reach prognostic significance. This finding might be influenced by sampling bias: Couvelard and colleagues showed that two randomly taken cores from the same metastasis of pancreatic NETs led to

B

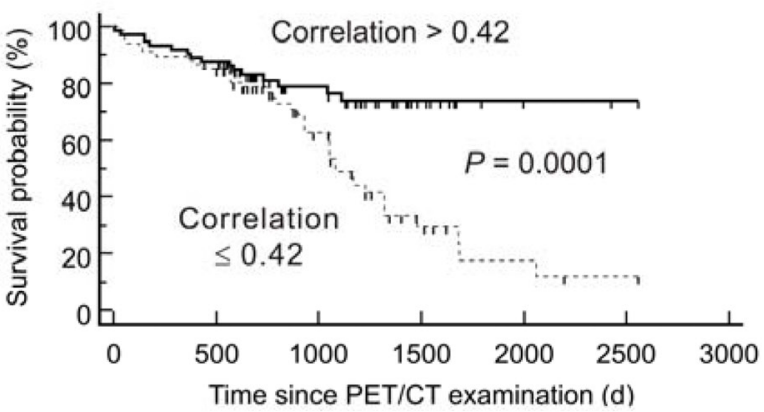

Number at risk:

\begin{tabular}{|l|r|r|r|r|r|r|r|}
\hline Time (d) & 0 & 500 & 1,000 & 1,500 & 2,000 & 2,500 & 3,000 \\
\hline Correlation > 0.42 & 74 & 64 & 32 & 12 & 2 & 1 & 0 \\
\hline Correlation $\leq 0.42$ & 67 & 56 & 29 & 8 & 3 & 1 & 0 \\
\hline
\end{tabular}

D

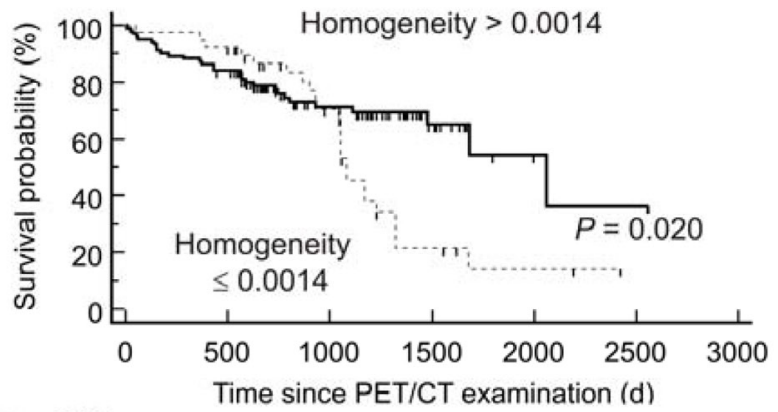

Number at risk:

\begin{tabular}{|l|r|r|r|r|r|r|r|}
\hline Time (d) & 0 & 500 & 1,000 & 1,500 & 2,000 & 2,500 & 3,000 \\
\hline $\begin{array}{l}\text { Homogeneity } \\
>0.0014\end{array}$ & 102 & 85 & 40 & 15 & 3 & 2 & 0 \\
\hline $\begin{array}{l}\text { Homogeneity } \\
\leq 0.0014\end{array}$ & 39 & 35 & 21 & 5 & 2 & 0 & 0 \\
\hline
\end{tabular}

Figure 2: Kaplan-Meier plots and number-at-risk tables for probability of Overall Survival $(\boldsymbol{n}=141)$. Low-risk group (solid lines) was identified by various textural parameters measured on somatostatin receptor positron emission tomography/computed tomography (PET/CT) before Peptide Receptor Radionuclide Therapy. Cut-off values derived by Receiver operating characteristics analysis were used. $\mathrm{d}=$ days. 

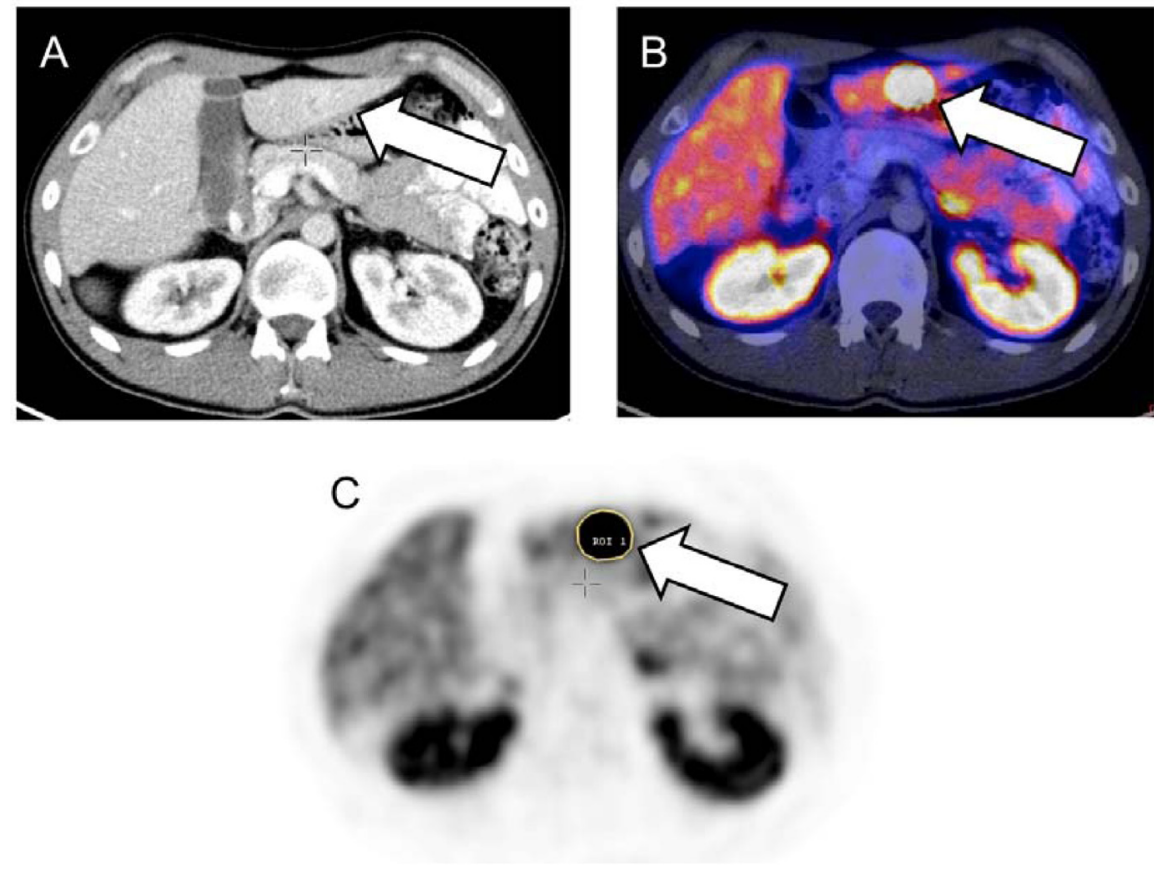

Figure 3.1: Baseline somatostatin receptor (SSTR) positron emission tomography/computed tomography (PET/CT) of a 24-year old male suffering from metastatic ileum neuroendocrine tumor. Liver metastasis can be detected on CT (A) and on SSTR-PET/CT (B) indicated by the arrows. Manual stepwise segmentation of the lesion (arrow) by a region of interest on the PET-only images was performed (C). An overview of investigated heterogeneity parameters can be found in [26, 27], Table 4 and Figure 3.2 .

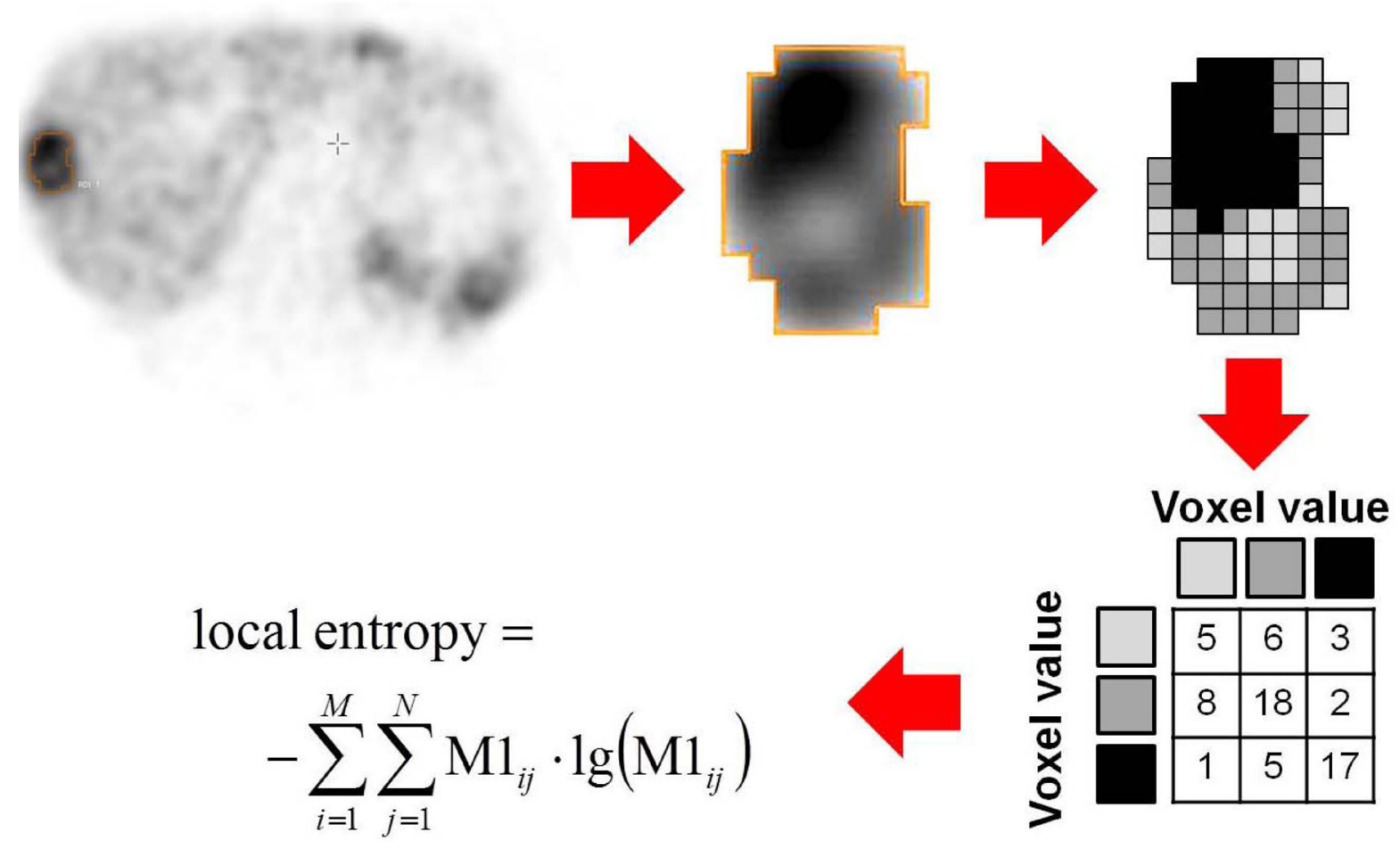

Figure 3.2: Schematic example of Entropy assessment as one of the heterogeneity parameters. Baseline somatostatin receptor positron emission tomography of a subject suffering from liver metastasis of a gastroenteric neuroendocrine tumor. Magnification of a liver metastasis demonstrates intralesional differences in ${ }^{68} \mathrm{Ga}$-DOTA-D-Phe-Tyr3-octreotate $\left({ }^{68} \mathrm{Ga}\right.$-DOTATATE) distribution. For calculation of Entropy as a second order textural parameter the activity values in the lesion are discretized and a spatial dependence matrix (M1) is created. M1 determines how often a pixel with intensity i finds itself within a certain relationship (e.g. next neighbor in one direction) to another pixel with intensity $\mathrm{j}$ in a volume of interest [28]. 
Table 3: Results of Kaplan-Meier analysis regarding for Progression-Free (PFS) and Overall Survival (OS).

\begin{tabular}{|l|l|l|l|l|l|l|l|}
\hline Parameter & for & $\mathbf{x}^{\mathbf{2}}$ & $\boldsymbol{p}$-value & HR negative & CI & HR positive & CI \\
\hline \multirow{2}{*}{ Entropy } & PFS & 7.14 & 0.007 & 1.87 & $1.09-3.19$ & 0.54 & $0.31-0.92$ \\
\cline { 2 - 8 } & OS & 14.45 & 0.0001 & 2.79 & $1.62-4.81$ & 0.36 & $0.21-0.62$ \\
\hline \multirow{2}{*}{ Correlation } & PFS & 7.85 & 0.005 & 1.9 & $1.14-3.16$ & 0.53 & $0.32-0.88$ \\
\cline { 2 - 9 } & OS & 11.31 & 0.0008 & 2.61 & $1.53-4.45$ & 0.38 & $0.23-0.65$ \\
\hline \multirow{2}{*}{ Short Zone Emphasis } & PFS & 7.99 & 0.004 & 1.87 & $1.17-3.0$ & 0.53 & $0.33-0.85$ \\
\cline { 2 - 8 } & OS & 12.91 & 0.0003 & 2.53 & $1.39-4.62$ & 0.4 & $0.22-0.72$ \\
\hline \multirow{2}{*}{ Homogeneity } & PFS & 3.71 & 0.05 & 1.58 & $1.0-2.49$ & 0.63 & $0.4-1.0$ \\
\cline { 2 - 8 } & OS & 5.41 & 0.01 & 1.86 & $1.04-3.33$ & 0.54 & $0.3-0.96$ \\
\hline TRE & OS & 10.39 & 0.001 & 2.34 & $1.25-4.36$ & 0.43 & $0.23-0.80$ \\
\hline
\end{tabular}

Whole cohort $(n=141), 75$ demonstrated progressive disease, 54 died. $\mathrm{CI}=$ confidence interval, HR $=$ Hazard Ratio, TRE $=$ tissue receptor expression (as a conventional positron emission tomography parameter).

Table 4: Overview of selected textural parameters.

\begin{tabular}{|c|c|c|}
\hline Parameter & Order & Description \\
\hline Coefficient of Variation (COV) & $1^{\text {st }}$ & A normalized measure of dispersion of a frequency distribution. \\
\hline Skewness & $1^{\text {st }}$ & $\begin{array}{l}\text { A measure for the extent to which a frequency distribution "leans" to side of the } \\
\text { mean value of the distribution. }\end{array}$ \\
\hline Entropy & $2^{\text {st }}$ & $\begin{array}{l}\text { Measures grade of derangement, e.g. a homogenous matrix demonstrates low } \\
\text { entropy. }\end{array}$ \\
\hline Homogeneity & $2^{\text {st }}$ & $\begin{array}{l}\text { A measure for continuous areas of same or similar voxel values in an image or } \\
\text { voxel of interest (VOI). }\end{array}$ \\
\hline Correlation & $2^{\text {st }}$ & A measure of intensity linear-dependencies. \\
\hline Contrast & $2^{\text {st }}$ & $\begin{array}{l}\text { Measures the difference of the grey value when going to the next voxel. It is high } \\
\text { when the intensity changes very often between single voxels. }\end{array}$ \\
\hline Short Zone Emphasis & $3^{\text {st }}$ & $\begin{array}{l}\text { Measures the distribution of short zones. It is highly dependent on the occurrence } \\
\text { of small zones and is expected to be large for fine textures. }\end{array}$ \\
\hline Size Variation & $3^{\text {st }}$ & Describes the variation in the size of different substructures in an image (VOI). \\
\hline
\end{tabular}

a change in grading in half of the cases [25]. Therefore, especially in patients with multiple lesions, non-invasive and reliable whole-body assessment of intra-tumor heterogeneity might yield completely different results [29] and contribute to individualised treatment decisions [30].

Diagnostic imaging of NET is the domain of SSTR agonists as well as ${ }^{18} \mathrm{~F}-\mathrm{FDG}$ PET/CT in case of dedifferentiation [31]. More recently, specific ligands targeting C-X-C motif chemokine receptor 4 (CXCR4) for diagnostic and therapeutic purposes were also introduced [32-37] and in the future, a combination of these abovementioned radionuclides might also potentially offer additional insight in NET biology and its underlying heterogeneity.

This study has several limitations: As disadvantage of a large multicentric trial, imaging as well as therapeutic protocols might differ from center to center. Especially when dealing with elaborated image analysis as textural features, varieties due to different PET/CT machines and different acquisition protocols may occur. However, using ${ }^{18} \mathrm{~F}-\mathrm{FDG}$, Tixier et al. proved robustness of certain local or regional characterization features (e.g. Entropy), which also reached significance in our analysis [38]. Moreover, we are aware of the multiple testing problem; however, even when we correct for alpha inflation, the majority of tests remain significant.

Though NET is a rare disease with an annual incidence of approximately 5 new cases per 100.000 inhabitants [1], we were able to enroll a cohort of more than 140 patients which underwent PRRT. Therefore, advantages for such a multicentric trial might overcome the disadvantage of different diagnostic or therapeutic protocols. Also the low incidence of this disease complicates prospective reproduction of such analysis, which would be still the next step to achieve more standardized results.

In conclusion, in this multicenter trial enrolling 141 patients, tumor heterogeneity as assessed by baseline SSTR-PET/CT proved prognostic value in PRRT candidates and outperformed common conventional PET parameters. Assessment of intratumoral heterogeneity might significantly contribute to a more individualized 
patient management and treatment tailoring.

\section{MATERIALS AND METHODS}

All patients gave written and informed consent to the treatment and imaging procedures. The study was approved by local institutional review boards or the requirement for additional approval was waived due to the retrospective character of this study.

\section{Patient population}

In a retrospective cohort, 142 patients (71/141 females $(50.4 \%), 63 \pm 11$ years, median $64 \mathrm{y}$, range, 24$83 \mathrm{y})$ at the four university hospitals of Bonn $(n=78)$, Wuerzburg $(n=27)$, Munich $(n=21)$ and Hannover $(n$ $=15$ ) were enrolled. Gastroenteropancreatic (GEP)-NET (including primary tumors of the pancreas, stomach, ileum/jejunum/mesenterium and colon) occurred in 108/141 (76.6\%) patients, 15/141 (10.6\%) were classified as cancer of unknown primary (CUP), 9/141 (6.4\%) had lung NET and the remaining 9 patients $(6.4 \%)$ suffered from other tumor entities (including meningeoma, hemangioendothelioma, pheochromocytoma, medullary thyroid carcinoma and pituitary tumor). Histological confirmation of the diagnosis was available in every patient. Proliferation index Ki67 ranged between 1-40\% with a median of $5 \%$. Chromogranin $\mathrm{A}(\mathrm{CgA})$ levels prior to therapy ranged between $35-64700 \mu \mathrm{g} / \mathrm{l}$ (median, 571 $\mu \mathrm{g} / \mathrm{l})$. All patients had undergone a number of previous treatments including surgery $(n=76 / 141,53.9 \%)$, sandostatin therapy $(n=79 / 141,56 \%)$, chemotherapy $(n$ $=39 / 141,27.7 \%)$, or external beam radiation therapy $(n=$ $15 / 141,10.6 \%$ ).

Clinical and routinely acquired characteristics of the patient cohort including sex, age, prior therapies, site of metastases, $\mathrm{CgA}$, Ki67, and administered activities are given in Table 1.

Radiopeptide therapy was performed according to the Rotterdam protocol as outlined by Kwekkeboom et al. as well as The joint IAEA, EANM and SNMMI practical guidance on a compassionate use basis, respectively [11, 19]. A total of 709 treatment cycles (median, 4, range, 1-6) with a median of 7.3 Gigabecquerel (GBq) (range, 0.9-9.0 GBq) per cycle with ${ }^{177}$ Lutetium $\left({ }^{177} \mathrm{Lu}\right)$-labeled somatostatin analog ( ${ }^{177} \mathrm{Lu}-\mathrm{DOTATATE} /-$ DOTA-DPhe-Tyr3-octreotide (DOTATOC)) were performed. Imaging including both functional (SSTR-PET/CT) and/ or morphologic imaging (CT) modalities was conducted every 3-6 months after PRRT [11]. PFS was defined according to Response Evaluation Criteria in Solid Tumors 1.1 (RECIST 1.1) by serial radiological assessment starting from the time point of baseline imaging and/or according to clinical signs of progression [11, 39. For the calculation of overall survival (OS) the time interval between the pre-therapeutic PET examination and the date of death was used.

\section{PET/CT imaging}

Prior to PRRT, all patients underwent SSTR-PET/ CT according to EANM guidelines to assess tumor receptor expression [11]. A median of 124 Megabecquerel (MBq) (range, 61-239 MBq) of ${ }^{68} \mathrm{Ga}$-DOTATATE/TOC was injected intravenously. After 60 minutes, imaging was performed using the following devices: Bonn, Biograph 2 PET/CT (Siemens Medical Solutions, Erlangen, Germany); Wuerzburg, Biograph 64 (Siemens Medical Solutions, Erlangen, Germany); Munich, Gemini TF PET/CT (Philips Medical, Eindhoven, Netherlands) or Siemens Biograph 64 (Siemens Medical Solutions, Erlangen, Germany); Hannover, Biograph 2 (Siemens Medical Solutions, Erlangen, Germany). All data was reconstructed using iterative algorithms implemented by the manufacturer and depending on the routine protocol of the different medical centers. Scatter and attenuation correction was performed based on the different transmission data.

\section{Image interpretation}

Analysis of the dataset was performed at the university hospitals of Bonn and Wuerzburg. All image data were transferred to an Interview Fusion Workstation (Mediso Medical Imaging Systems Ltd., Budapest, Hungary). Conventional parameters (such as $\mathrm{SUV}_{\text {mean }} / \mathrm{SUV}_{\max }$, TRE)) were derived. TRE is the product of segmented lesion volume times the mean activity uptake, analog to the total lesion glycolysis in ${ }^{18} \mathrm{~F}$-fluorodeoxyglucose $\left({ }^{18} \mathrm{~F}\right.$-FDG) PET. For analysis of tumor heterogeneity the largest lymph node, bone and visceral metastases were assessed. For systembased analysis the mean value of these lesions for each individual system was used. For patient-based analysis, the mean value of all segmented lesions per patient was performed. Metastases smaller than $15 \mathrm{~mm}$ were not taken into account to avoid partial volume effects. Manual segmentation was executed in combined PET/ CT data (Figure 3.1). Several different textural parameters representing intratumoral heterogeneity were derived from every individual lesion and were divided in first order parameters (e.g., Coefficient of variation, COV), second order parameters (e.g., Entropy, Correlation) and higher order parameters (e.g., Grey Level Uniformity, Intensity Variation, Short Zone Emphasis). A detailed description can be found in Table 4, Figure 3.2, [26] and [27]. For comparison to heterogeneity parameters, conventional diagnostic parameters were evaluated: morphologic volume of the lesion, maximum standardized uptake value $\left(\mathrm{SUV}_{\text {max }}\right)$, mean SUV (SUV mean $)$, and TRE were assessed. 
The SUV was calculated according to the body weight of the patient. In total, 872 lesions (median, 6, range, 1-23 per patient) were manually segmented.

\section{Statistical analysis}

First, Cox multiparametric regression was applied to determine independent prognostic parameters of PFS and OS as well as estimation of HR. Due to multi-colinearity of different textural parameters, only the following parameters were included in the final Cox regression: COV, Skewness, Entropy, Homogeneity, Correlation, Contrast, Short Zone Emphasis and Size Variation. For all independent parameters, ROC analysis was obtained to estimate the optimal cut-off value for the individual parameters to assess progress and OS in the follow-up period. For this purpose, the Youden index was used to maximize the sum of sensitivity and specificity [40]. The area under curve (AUC) was calculated including the exact binominal confidence intervals $(95 \%$ confidence level). Statistical significance of the prognostic capability was assumed when the critical value of 0.5 was not included in the confidence interval. For the parameters showing such significance, the relationship to both PFS and OS was analyzed using Kaplan-Meier plots. KaplanMeier analysis was performed using thresholds established by prior ROC analysis. Differences between Kaplan-Meier curves were evaluated using nonparametric log-rank tests, considering differences with a $p$ value smaller than 0.05 to be significant.

Cox analysis was executed using the software package $\mathrm{R}$ (version 3.2.4, www.r-project.org). ROC analysis and Kaplan-Meier analysis was performed using MedCalc software (version 12.3.0.0, MedCalc Mariakerke, Belgium).

\section{CONFLICTS OF INTEREST}

All authors had full control of the data and information submitted for publication. RB has a noncommercial research contract with Mediso Medical Imaging Systems, RB is on the speaker's bureau for Mediso Medical Imaging Systems, and NZ is employed by Mediso Medical Imaging Systems, LP was employed by Mediso Medical Imaging Systems while largest parts of the study were performed. All other authors had full control of the data and information submitted for publication. No potential conflicts of interest were disclosed by the other authors.

Parts of this work have been presented at the Annual Meeting of the Society of Nuclear Medicine and Molecular Imaging, 2016, San Diego, United States.

\section{Editorial note}

This paper has been accepted based in part on peerreview conducted by another journal and the authors' response and revisions as well as expedited peer-review in Oncotarget.

\section{REFERENCES}

1. Kulke MH, Siu LL, Tepper JE, Fisher G, Jaffe D, Haller DG, Ellis LM, Benedetti JK, Bergsland EK, Hobday TJ, Van Cutsem E, Pingpank J, Oberg K, Cohen SJ, Posner $\mathrm{MC}$ and Yao JC. Future directions in the treatment of neuroendocrine tumors: consensus report of the National Cancer Institute Neuroendocrine Tumor clinical trials planning meeting. J Clin Oncol. 2011; 29(7):934-943.

2. Gerlinger M, Rowan AJ, Horswell S, Larkin J, Endesfelder D, Gronroos E, Martinez P, Matthews N, Stewart A, Tarpey P, Varela I, Phillimore B, Begum S, et al. Intratumor heterogeneity and branched evolution revealed by multiregion sequencing. N Engl J Med. 2012; 366(10):883892.

3. Rinke A, Muller HH, Schade-Brittinger C, Klose KJ, Barth P, Wied M, Mayer C, Aminossadati B, Pape UF, Blaker M, Harder J, Arnold C, Gress T, Arnold R and Group PS. Placebo-controlled, double-blind, prospective, randomized study on the effect of octreotide LAR in the control of tumor growth in patients with metastatic neuroendocrine midgut tumors: a report from the PROMID Study Group. J Clin Oncol. 2009; 27(28):4656-4663.

4. Bundschuh RA, Dinges J, Neumann L, Seyfried M, Zsoter N, Papp L, Rosenberg R, Becker K, Astner ST, Henninger M, Herrmann K, Ziegler SI, Schwaiger M and Essler M. Textural Parameters of Tumor Heterogeneity in 18F-FDG PET/CT for Therapy Response Assessment and Prognosis in Patients with Locally Advanced Rectal Cancer. J Nucl Med. 2014; 55(6):891-897.

5. Cook GJ, O'Brien ME, Siddique M, Chicklore S, Loi HY, Sharma B, Punwani R, Bassett P, Goh V and Chua S. Non-Small Cell Lung Cancer Treated with Erlotinib: Heterogeneity of F-FDG Uptake at PET-Association with Treatment Response and Prognosis. Radiology. 2015:141309.

6. Lapa C, Werner RA, Schmid JS, Papp L, Zsoter N, Biko J, Reiners C, Herrmann K, Buck AK and Bundschuh RA. Prognostic value of positron emission tomographyassessed tumor heterogeneity in patients with thyroid cancer undergoing treatment with radiopeptide therapy. Nucl Med Biol. 2015; 42(4):349-354.

7. Ruszniewski. 177-Lu-Dotatate significantly improves progression-free survival in patients with mid-gut neuroendocrine tumours: Results of the phase III NETTER-1 trial. 40th Congress, European Society for Medical Oncology, Presidental Session. 2015. 
8. Strosberg J, Wolin E, Chasen B, Kulke M, Bushnell D, Caplin M, Baum RP, Mittra E, Hobday T, Hendifar A, Oberg K, Sierra ML, Kwekkeboom D, et al. 177-LuDotatate Significantly Improves Progression-Free Survival in Patients with Midgut Neuroendocrine Tumors: Results of the Phase III NETTER-1 Trial. Pancreas. 2016; 45(3):483483.

9. Werner RA, Beykan S, Higuchi T, Luckerath K, Weich A, Scheurlen M, Bluemel C, Herrmann K, Buck AK, Lassmann M, Lapa C and Hanscheid H. The impact of 177Lu-octreotide therapy on 99mTc-MAG3 clearance is not predictive for late nephropathy. Oncotarget. 2016; 7:4123341241. doi: 10.18632/oncotarget.9775.

10. Massironi S, Rossi RE, Zilli A, Casazza G, Ciafardini C and Conte D. A wait-and-watch approach to small pancreatic neuroendocrine tumors: prognosis and survival. Oncotarget. 2016; 7:18978-18983. doi: 10.18632/oncotarget. 7902.

11. Bodei L, Mueller-Brand J, Baum RP, Pavel ME, Horsch D, O'Dorisio MS, O’Dorisio TM, Howe JR, Cremonesi M, Kwekkeboom DJ and Zaknun JJ. The joint IAEA, EANM, and SNMMI practical guidance on peptide receptor radionuclide therapy (PRRNT) in neuroendocrine tumours. Eur J Nucl Med Mol Imaging. 2013; 40(5):800-816.

12. Sadowski SM, Neychev V, Millo C, Shih J, Nilubol N, Herscovitch P, Pacak K, Marx SJ and Kebebew E. Prospective Study of 68Ga-DOTATATE Positron Emission Tomography/Computed Tomography for Detecting GastroEntero-Pancreatic Neuroendocrine Tumors and Unknown Primary Sites. J Clin Oncol. 2016; 34(6):588-596.

13. Ganeshan B, Panayiotou E, Burnand K, Dizdarevic S and Miles K. Tumour heterogeneity in non-small cell lung carcinoma assessed by CT texture analysis: a potential marker of survival. Eur Radiol. 2012; 22(4):796-802.

14. Lopes R, Ayache A, Makni N, Puech P, Villers A, Mordon $\mathrm{S}$ and Betrouni N. Prostate cancer characterization on MR images using fractal features. Med Phys. 2011; 38(1):83-95.

15. O'Connor JP, Rose CJ, Jackson A, Watson Y, Cheung S, Maders F, Whitcher BJ, Roberts C, Buonaccorsi GA, Thompson G, Clamp AR, Jayson GC and Parker GJ. DCEMRI biomarkers of tumour heterogeneity predict CRC liver metastasis shrinkage following bevacizumab and FOLFOX-6. Br J Cancer. 2011; 105(1):139-145.

16. Groheux D, Majdoub M, Tixier F, Le Rest CC, Martineau A, Merlet P, Espie M, de Roquancourt A, Hindie E, Hatt $M$ and Visvikis D. Do clinical, histological or immunohistochemical primary tumour characteristics translate into different (18)F-FDG PET/CT volumetric and heterogeneity features in stage II/III breast cancer? Eur J Nucl Med Mol Imaging. 2015; 42(11):1682-1691.

17. Tixier F, Le Rest CC, Hatt M, Albarghach N, Pradier $\mathrm{O}$, Metges JP, Corcos L and Visvikis D. Intratumor heterogeneity characterized by textural features on baseline 18F-FDG PET images predicts response to concomitant radiochemotherapy in esophageal cancer. J Nucl Med. 2011; 52(3):369-378.
18. Hatt M, Majdoub M, Vallieres M, Tixier F, Le Rest CC, Groheux D, Hindie E, Martineau A, Pradier O, Hustinx R, Perdrisot R, Guillevin R, El Naqa I and Visvikis D. 18F-FDG PET uptake characterization through texture analysis: investigating the complementary nature of heterogeneity and functional tumor volume in a multicancer site patient cohort. J Nucl Med. 2015; 56(1):38-44.

19. Kwekkeboom DJ, de Herder WW, Kam BL, van Eijck CH, van Essen M, Kooij PP, Feelders RA, van Aken MO and Krenning EP. Treatment with the radiolabeled somatostatin analog [177 Lu-DOTA 0,Tyr3] octreotate: toxicity, efficacy, and survival. J Clin Oncol. 2008; 26(13):2124-2130.

20. Gopinath G, Ahmed A, Buscombe JR, Dickson JC, Caplin $\mathrm{ME}$ and Hilson AJ. Prediction of clinical outcome in treated neuroendocrine tumours of carcinoid type using functional volumes on $111 \mathrm{In}$-pentetreotide SPECT imaging. Nucl Med Commun. 2004; 25(3):253-257.

21. Kwekkeboom DJ, Teunissen JJ, Bakker WH, Kooij PP, de Herder WW, Feelders RA, van Eijck CH, Esser JP, Kam BL and Krenning EP. Radiolabeled somatostatin analog [177Lu-DOTA0,Tyr3] octreotate in patients with endocrine gastroenteropancreatic tumors. J Clin Oncol. 2005; 23(12):2754-2762.

22. Deppen S, Blume J, Bobbey AJ, Shah C, Graham MM, Lee $\mathrm{P}$ and Walker RC. 68Ga-DOTATATE compared to $111 \mathrm{In}$ octreotide and conventional imaging for pulmonary and gastroenteropancreatic neuroendocrine tumors: a systematic review and meta-analysis. J Nucl Med. 2016.

23. Haug AR, Auernhammer CJ, Wangler B, Schmidt GP, Uebleis C, Goke B, Cumming P, Bartenstein P, Tiling R and Hacker M. 68Ga-DOTATATE PET/CT for the early prediction of response to somatostatin receptor-mediated radionuclide therapy in patients with well-differentiated neuroendocrine tumors. J Nucl Med. 2010; 51(9):13491356.

24. Gabriel M, Oberauer A, Dobrozemsky G, Decristoforo C, Putzer D, Kendler D, Uprimny C, Kovacs P, Bale R and Virgolini IJ. 68Ga-DOTA-Tyr3-octreotide PET for assessing response to somatostatin-receptor-mediated radionuclide therapy. J Nucl Med. 2009; 50(9):1427-1434.

25. Couvelard A, Deschamps L, Ravaud P, Baron G, Sauvanet A, Hentic O, Colnot N, Paradis V, Belghiti J, Bedossa P and Ruszniewski P. Heterogeneity of tumor prognostic markers: a reproducibility study applied to liver metastases of pancreatic endocrine tumors. Mod Pathol. 2009; 22(2):273281.

26. Chicklore S, Goh V, Siddique M, Roy A, Marsden PK and Cook GJ. Quantifying tumour heterogeneity in 18F-FDG PET/CT imaging by texture analysis. Eur J Nucl Med Mol Imaging. 2013; 40(1):133-140.

27. Werner RA, Kroiss M, Nakajo M, Mugge DO, Hahner S, Fassnacht M, Schirbel A, Bluemel C, Higuchi T, Papp L, Zsoter N, Buck AK, Bundschuh RA, et al. Assessment of tumor heterogeneity in treatment-naive adrenocortical cancer patients using F-FDG positron emission tomography. 
Endocrine. 2016.

28. Buvat I, Orlhac F and Soussan M. Tumor Texture Analysis in PET: Where Do We Stand? J Nucl Med. 2015; 56(11):1642-1644.

29. Yang Z, Tang LH and Klimstra DS. Effect of tumor heterogeneity on the assessment of Ki67 labeling index in well-differentiated neuroendocrine tumors metastatic to the liver: implications for prognostic stratification. Am J Surg Pathol. 2011; 35(6):853-860.

30. Sala E, Vargas HA, Donati OF, Weber WA and Hricak $\mathrm{H}$. Role of molecular imaging in the era of personalized medicine: A review. Functional Imaging in Oncology. 2014:43- 58.

31. Lapa C, Werner RA and Herrmann K. Visualization of tumor heterogeneity in neuroendocrine tumors by positron emission tomography. Endocrine. 2016; 51(3):556557.

32. Philipp-Abbrederis K, Herrmann K, Knop S, Schottelius M, Eiber M, Luckerath K, Pietschmann E, Habringer S, Gerngross C, Franke K, Rudelius M, Schirbel A, Lapa C, et al. In vivo molecular imaging of chemokine receptor CXCR4 expression in patients with advanced multiple myeloma. EMBO Mol Med. 2015; 7(4):477-487.

33. Lapa C, Luckerath K, Rudelius M, Schmid JS, Schoene A, Schirbel A, Samnick S, Pelzer T, Buck AK, Kropf S, Wester HJ and Herrmann K. [68Ga]Pentixafor-PET/CT for imaging of chemokine receptor 4 expression in small cell lung cancer - initial experience. Oncotarget. 2016; 7:92889295. doi: 10.18632/oncotarget.7063.

34. Thackeray JT, Derlin T, Haghikia A, Napp LC, Wang Y, Ross TL, Schafer A, Tillmanns J, Wester HJ, Wollert KC, Bauersachs J and Bengel FM. Molecular Imaging of the Chemokine Receptor CXCR4 After Acute Myocardial Infarction. JACC Cardiovasc Imaging. 2015; 8(12):14171426.
35. Lapa C, Luckerath K, Kleinlein I, Monoranu CM, Linsenmann T, Kessler AF, Rudelius M, Kropf S, Buck AK, Ernestus RI, Wester HJ, Lohr M and Herrmann K. (68)Ga-Pentixafor-PET/CT for Imaging of Chemokine Receptor 4 Expression in Glioblastoma. Theranostics. 2016; 6(3):428-434.

36. Kaemmerer D, Trager T, Hoffmeister M, Sipos B, Hommann M, Sanger J, Schulz S and Lupp A. Inverse expression of somatostatin and CXCR4 chemokine receptors in gastroenteropancreatic neuroendocrine neoplasms of different malignancy. Oncotarget. 2015; 6:27566-27579. doi: 10.18632/oncotarget.4491.

37. Kaemmerer D, Reimann C, Specht E, Wirtz RM, Sayeg M, Baum RP, Schulz S and Lupp A. Differential expression and prognostic value of the chemokine receptor CXCR4 in bronchopulmonary neuroendocrine neoplasms. Oncotarget. 2015; 6:3346-3358. doi: 10.18632/oncotarget.3242.

38. Tixier F, Hatt M, Le Rest CC, Le Pogam A, Corcos L and Visvikis D. Reproducibility of tumor uptake heterogeneity characterization through textural feature analysis in 18F-FDG PET. J Nucl Med. 2012; 53(5):693-700.

39. Eisenhauer EA, Therasse P, Bogaerts J, Schwartz LH, Sargent D, Ford R, Dancey J, Arbuck S, Gwyther S, Mooney M, Rubinstein L, Shankar L, Dodd L, et al. New response evaluation criteria in solid tumours: revised RECIST guideline (version 1.1). Eur J Cancer. 2009; 45(2):228-247.

40. Youden WJ. Index for rating diagnostic tests. Cancer. 1950; 3(1):32-35. 